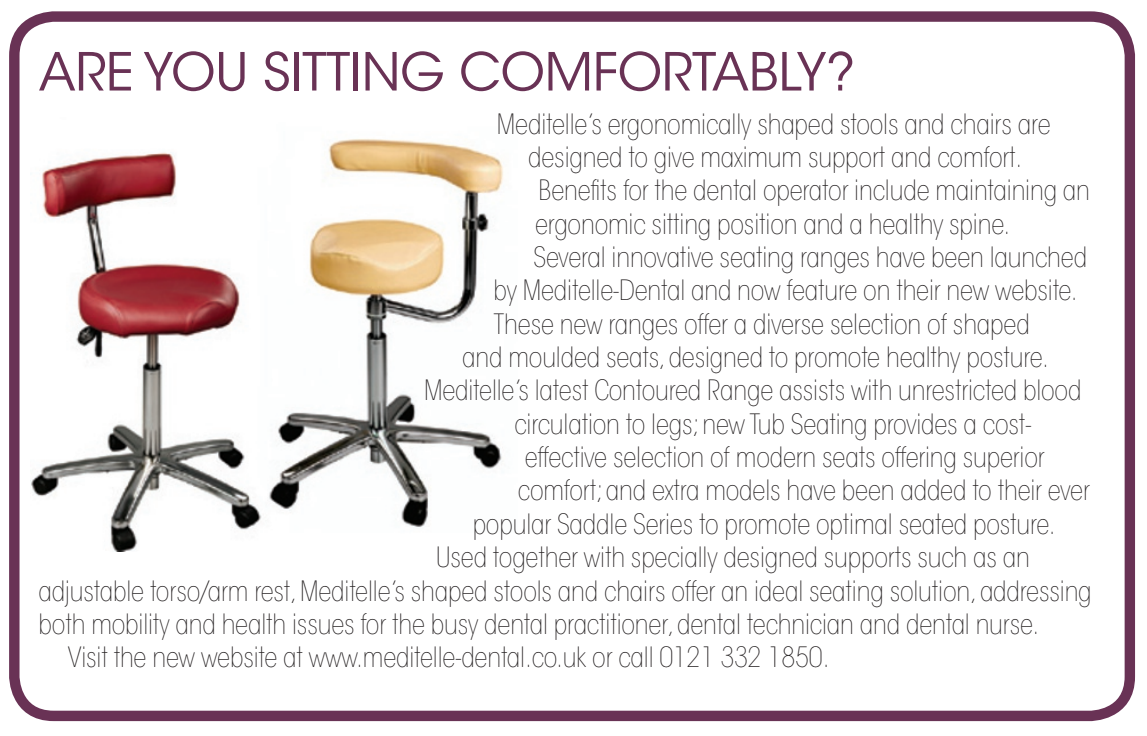

\title{
GUM PROBLEMS? CORSODYL
}

Recent research conducted by GlaxoSmithKline Consumer Healthcare amongst dental professionals confirms that Corsodyl is the number 1 recommended brand for the treatment of gum problems.

Ninety-nine percent of dentists surveyed stated that they trust Corsodyl as a treatment for patients with gingivitis.! The Corsodyl brand is synonymous with gum health and Corsodyl is the market leading treatment mouthwash range?

The Corsodyl brand is committed to helping raise awareness of the importance of gum health with patients and the significance of bleeding when brushing as an early sign of gum disease. As part of this campaign Corsodyl Gum Care Packs containing education materials incorporating the BPE examination are available for dental practices at www.gsk-dentalprofessionals.co.uk

\section{VISIT THE SENSODYNE AND CORSODYL STAND!}

Join GlaxoSmithKline Consumer Healthcare (GSK) to find out more about Sensodyne and Corsodyl on stand HO4 at the BDTA Dental Showcase, 17-19 October, Birmingham NEC

The stand will feature information about NEW Sensodyne Complete Protection, which is powered by NovalMin technology. Sensodyne Complete Protection offers all-round care for dentine hypersensitivity

sufferers, with twice daily brushing.

Also discover why Corsodyl is the number 1 dentist recommended brand for gum problems.' Corsody

reatment mouthwash (chlorhexidine digluconate) treats and prevents gingivitis, with twice daily use. The GSK team will be available to provide toothpaste samples and discuss products. To request samples of GSK products for your patients, visit www. gsk-dentalprofessionals.co.uk.

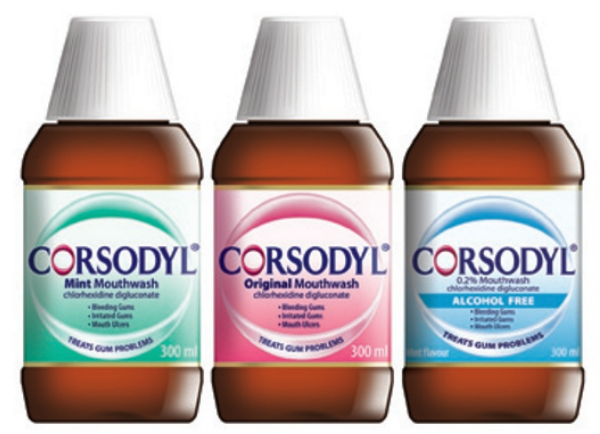

\section{COMPLETE TOOTHPASTE FOR SENSITIVE TEETH}

When patients suffer from dentine hypersensitivity, as a dental professional you may recommend a specialist toothpaste to relieve the pain. However, many patients seek all-round oral care benefits in addition to sensitivity relief which may prevent them from changing their toothpaste and treating the condition.

GlaxoSmithKline Consumer Healthcare (GSK) announces the launch of new Sensodyne Complete Protection - offering all-round care for dentine hypersensitivity patients (with twice daily brushing). ${ }^{1-6}$ Sensodyne Complete Protection is one complete sensitivity toothpaste that contains seven specially designed patient benefits (with twice daily brushing).

Sensodyne Complete Protection is powered by NovaMin technology, a bioactive

technology originally developed for bone repair. Sensodyne Complete Protection:

- Delivers clinically proven relief from the pain of dentine hypersensitivity

- Contains fluoride to strengthen ename

- Helps to maintain gingival health. ${ }^{4}$

NovaMin technology releases calcium and phosphate on contact with saliva to form a layer of protection over exposed dentine and within dentine tubules ${ }^{7-12}$ which s up to $50 \%$ harder than dentine. ${ }^{8,12}$ This layer begins to form from the first use.,8, and binds firmly to the dentine making it resistant to daily oral challenges such as acidic food and drinks or toothbrushing. ${ }^{8}$.

NovaMin is unique in that it's the first material that will repair the vulnerable areas of sensitive teeth using the natural building blocks of teeth, calcium and phosphorous. It is breakthrough science that offers a real benefit for patients of hypersensitivity

Recommend Sensodyne Complete Protection to your patients with dentine hypersensitivity that want all-round care for their sensitive teeth

Du M Q Bian Z. Jiang $\mathrm{H}$ et al. Clinical evaluation of a dentifrice containing calcium sodium phosilicate

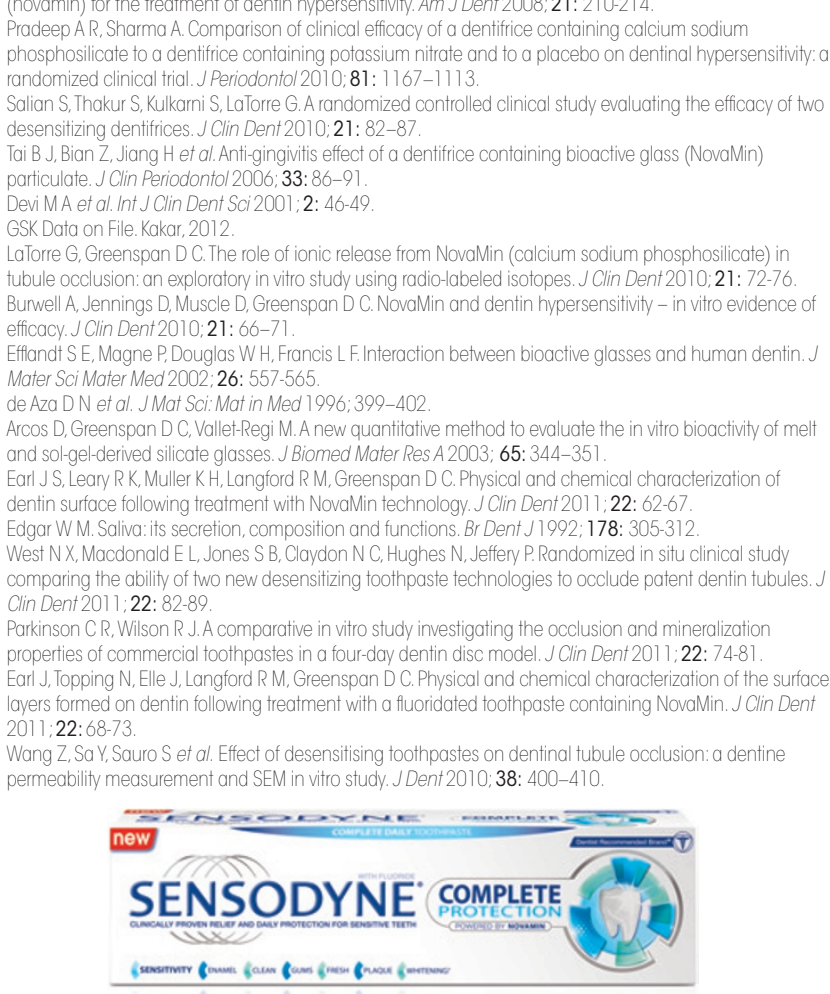

If you would like to promote your products or services direct to the dental industry through VITAL UPDATE telephone Steve Brown on 02078434724. 